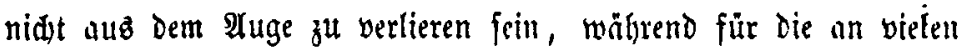
Drten und namentlid) aud) in Şolland fiemlid in's (Setvidst fallende Berwendung ju Bohnenftangen und Tabafipillen beibe Sgolzarter gleiden $\mathfrak{B e r t h}$ haben dürften.

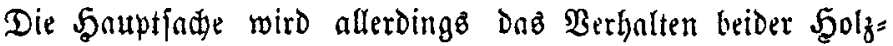
arten auf Dem gegebnen Boden und im Drua Dez Dverftandes

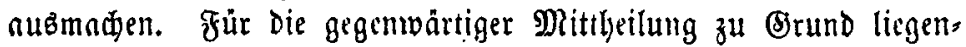
Den Dertlidffiten wird man nidt gerne bon Der Edwwarzerle laffen wollen, daz joll aber nidjt abknlten, dak aum mit Der $\mathfrak{B}$ Beißerle Berjuge gemadt werden. Die viel zu Innginm wadjende Buđe

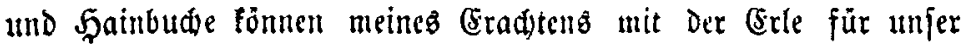
Berfabren nidbt coucuriten, und fönnten nur etwa Da in Betradjt fommen, two Der Boden für beide Erlenarten fid) Durdjaub unth = träglidy erweiòt. Ân Diefen Drten wird aber nud) für Die (Eid)e

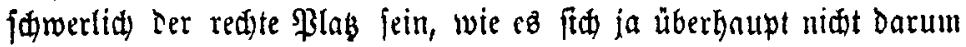

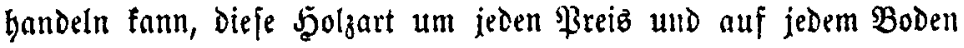
zu er Wirthjđafter Darfeflt, Den entipredenden Stnudort zu wählen, und wo Diejer nidı! mit hinlänglidjer Siđjerkeit gegeben ift, lieber bon Der (Eidjenzudit ganz abjujetgen.

\title{
Alaurderteri.
}

\section{Gin ungeraber $\mathbb{Z}$ wölfer.}

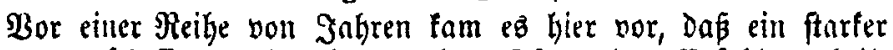

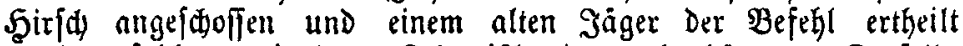

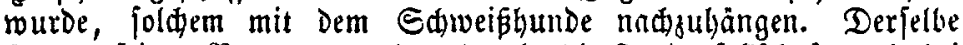
ftattete feinen Rapport gerade ab, nlo Die Jagogejellifaft now bei Ti门币e \{aß.

Da erfterer gut auzigefallen, erhiclt Der Säger ein Brlnz Deffertwein, ber ifm befonders gut mundete, er madte debgalb ein Beiden feiner Zufriedenheit. Der GngDherr bemerfte dieß und fagle: "ja baz war ebell Elfer*!" worauf Der Gäger im Ernfte: "ien hab" id jegt für 3 wölfer getrunten**

3ringenberg im Fiotrar 1868.

fiotb.

* Bom berübmten $\mathfrak{s} \mathfrak{a g} \mathfrak{g} \mathfrak{a n g} 1811$.

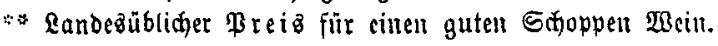

Birantwortlider \$ledacteur: Dr. Fr. Sanr, Profeffor an ber Mtabenie 5obenbeim.

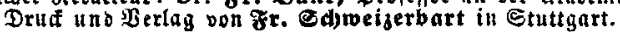

